\title{
A New Approach to Rank Forecasters in an Unbalanced Panel
}

\author{
John Silvia $^{1}$ \& Azhar Iqbal ${ }^{1}$ \\ ${ }^{1}$ Wells Fargo Securities, LLC, 301 South College Street, D1053-077, Charlotte, NC 28288, USA \\ Correspondence: Azhar Iqbal, Vice President and Econometrician, Wells Fargo Securities, LLC, 301 South \\ College Street, D1053-077, Charlotte, NC 28288, USA. Tel: 1-704-383-6805. E-mail: \\ azhar.iqbal@wellsfargo.com
}

$\begin{array}{lcc}\text { Received: May 14, } 2012 & \text { Accepted: June 25, } 2012 & \text { Online Published: July 30, } 2012 \\ \text { doi:10.5539/ijef.v4n9p108 } & \text { URL: http://dx.doi.org/10.5539/ijef.v4n9p108 }\end{array}$

\begin{abstract}
This study presents a new approach to ranking professional forecasters in an unbalanced panel. Ranking professional forecasters while not accounting for missing forecasts can lead to arbitrary results particularly depending on the forecasted variable and time period chosen. Here, our focus is on a third, very important but neglected, factor - the missing forecast. This paper identifies some serious issues related to the current methodology of some organizations, here we use the Bloomberg Survey as an example although Bloomberg is not alone with this problem.
\end{abstract}

We re-rank top-10 forecasters of nonfarm payrolls using a new approach which accounts for missing forecasts. For many forecasters, the ranking based on our approach is significantly different than those of Bloomberg's ranking. For instance, Bloomberg declared Credit Agricole as a winner (rank 1) but the new approach assigned $10^{\text {th }}$ position (rank 10) to Credit Agricole. One major reason of different rankings for a firm is that Credit Agricole did not forecast for all 24 months and it was rewarded in the Bloomberg methodology for being absent in certain months. Our methodology does not reward a forecaster for being absent nor does it penalize a forecaster for submitting a forecast and thereby provides a fairer, more rigorous and accurate ranking.

In addition, traditional forecast evaluation criteria, such as, MAE, MSE or RMSE are good for a balanced panel but not accurate for an unbalanced panel. Our approach provides a more rigorous and accurate forecasters ranking for any unbalanced panel.

Keywords: forecasters' ranking, unbalanced panel, Bloomberg, forecast error

JEL Classification: C5; C53; E27.

\section{Introduction}

This paper proposes a new approach which provides a more rigorous and accurate professional forecasters' ranking in an unbalanced panel. This study also identifies some serious issues related to the current Bloomberg methodology to rank forecasters. The top-10 forecasters of nonfarm payrolls are identified based on the new approach.

Many media services rank professional forecasters every year, i.e., Bloomberg publishes a list of top-10 forecasters for many macroeconomic variables. The ranking from Bloomberg (for example) is very important for a professional forecaster to demonstrate forecasting accuracy to his clients. An accurate ranking is also crucial for Bloomberg because a fair and accurate ranking would increase Bloomberg's credibility as a source of market intelligence.

Our study sheds light on four important areas of professional forecasters' ranking. First, recent study by Silvia and Iqbal (2010) suggests that scheduled macroeconomic variables release announcements affect asset prices and volatility in bond, equity and foreign exchange (FX) markets. Moreover the affect is more significant when an actual release is different than market expectations and many studies have used the Bloomberg consensus as a proxy for market expectations (see Rigobon and Sach (2008) and Bartolini et al. (2008) for more detail). Therefore, the importance of an individual forecaster's accuracy, which is better than consensus as well as other forecasters, is increased. In addition, a ranking from media services such as Bloomberg will be a strong evidence of forecasting accuracy for a professional forecaster. An accurate forecasters' ranking is also crucial for 
Bloomberg (or any other media service) because accurate ranking would increase Bloomberg credibility as sources of market intelligence (see next section for more detail).

Second, our analysis discusses the current Bloomberg methodology and re-produces top-10 forecasters of nonfarm payrolls for the same time period by using the same methodology, see section three for more detail. Third, issues related to the current Bloomberg methodology are discussed in section three. For instance, not all forecasters forecast every month and some of them have missing forecast for several months. This implies that it is an unbalanced panel. Bloomberg's methodology is good for a balanced panel but not accurate for an unbalanced panel. The first issue related to the current Bloomberg methodology is that it considers, implicitly, a missing forecast will equal to a perfect forecast for a given month. For instance, if a forecast is not available for a month from a forecaster then Bloomberg, implicitly, considers forecast error equals to zero for that month for that forecaster. Interestingly, if a forecaster makes a perfect forecast (forecast equals to actual release) then the forecast error will be zero for that forecaster for that month. This implies that a missing forecast is valued as equal to a perfect forecast. The second problem for the current methodology is that for a given month a forecaster, who makes a forecast for that month, is competing against a forecaster who does not make a forecast for that month. It would be fairer to compete against those who makes forecast for a given month, see section three for more detail.

Finally, a new approach is proposed, which provides a fairer, more rigorous and accurate forecasters' ranking in an unbalanced panel. Our methodology is based on ranks - where a lowest rank (rank 1) is associated with the smallest forecast error for a given month. In a first step, for a given month, we rank only those forecasters who makes forecast for that month. That limits competition among those who forecasted and eliminate those who do not forecast for a given month. As a result, this would be a solution to the second problem related to the current Bloomberg methodology. In the second step, we calculate average rank of a month and use that average rank for those forecasters who do not submit their forecast to Bloomberg for that month. In that way no forecaster will get rewarded for being absent or be penalized by submitting a forecast especially in times of greater data volatility. Hence it provides a solution to the first problem related to the current Bloomberg methodology, see section four for more detail. Our methodology provides more accuracy and can be used for professional forecasters' ranking in any unbalanced panel.

We re-rank top-10 forecasters of nonfarm payrolls using the new approach. For many forecasters, the ranking based on our approach is significantly different than those of Bloomberg's ranking. For instance, Bloomberg declares Credit Agricole as a winner (rank 1) but the new approach assigns $10^{\text {th }}$ position (rank 10) to Credit Agricole. On the other hand, Bloomberg associates rank 5 to CIBC World Markets (CIBC) but the new approach declares CIBC as a winner (rank 1). One major reason of these two different rankings for a firm is that Credit Agricole does not forecast for all 24 months (forecasted for 21 months) and CIBC forecasted for all 24 months. Moreover, Credit Agricole is rewarded in the Bloomberg methodology for being absent and CIBC penalized by submitting forecasts for all 24 months when some of these months (May/June for example) are known to be particularly volatile. On the other hand, our methodology does not give any reward for being absent or penalize a forecaster for submitting a forecast and thereby provides a fairer, more rigorous and accurate ranking. Because a ranking should be based on forecast accuracy (on average smaller forecast error compared to others) and should not give a benefit to absent forecasters or a disadvantage to those who regularly make forecasts, see section four for more detail.

The rest of the paper organized as follow; section 2 describes the importance of Bloomberg ranking. The current Bloomberg methodology and issues related to that approach are reviewed in section 3. Section 4 introduces a new approach to rank professional forecasters in an unbalanced panel. The concluding remarks are gathered in section 5 .

\section{Importance of the Bloomberg Ranking}

Before we discuss the current Bloomberg approach to rank professional forecasters and issues related to that methodology the natural question will arise; why are forecasters' rankings important to professional forecasters and to Bloomberg itself? The answer to this question reflects the central role of economic incentives. For instance, a large number of professional forecasters (in some cases more than 70) submit their forecasts, prior to a variable release announcement, to Bloomberg for many macroeconomic variables. Bloomberg provides a summary list of top forecasters for many macroeconomic variables every year. These rankings are based on a real-time short-term (one-month ahead) forecast. For professional forecasters, there is a monetary incentive to produce accurate forecasts of key macroeconomic variables prior to their release announcements, because, better forecasts of macroeconomic variables, prior to their release, will provide more opportunities to a firm to profit or 
at least reduce losses on economy-based forecasts. The empirical evidence of the relationship between financial markets volatility and scheduled macroeconomic variables' release announcements goes back to 1980s (see Schwert (1981) for detail). More recent studies, such as Anderson at al. (2007), Rigobon and Sach (2008) and Silvia and Iqbal (2010), suggest that key macroeconomic variables release announcements affect asset prices and volatility in financial markets, however, the affect is more significant when the actual release is different than the market expectations. (Note 1) Therefore, an individual forecaster, who is better than consensus and other forecasters, can provides more opportunities to his/her firm and clients to make money (or reduce losses). Keeping that in mind, a ranking from Bloomberg is very important for a forecaster to demonstrate forecasting accuracy to his/her clients. On the other hand, since Bloomberg is a major source of market information and an accurate ranking would increase Bloomberg's creditability as a source of market intelligence.

In sum, an accurate forecasters' ranking is a win-win outcome for both professional forecasters and Bloomberg. From an individual forecaster point of view, a ranking from a major market information/intelligence provider would be reliable evidence of forecasting accuracy. For Bloomberg, an accurate ranking will increase Bloomberg's credibility as an accurate/reliable information provider.

\section{The Current Bloomberg Methodology}

Bloomberg publishes a list of top forecasters (usually top-10) for many macroeconomic variables every year. For this study we select top- 10 forecasters of nonfarm payrolls. One major reason for selecting nonfarm payrolls as a case study is that the employment-related data release announcement is the most influential data release. Anderson at al. (2007) called employment data release as "King of all releases" and bond, equity and foreign exchange (FX) markets sharply respond to the employment-situation data release when it differs significantly from expectations. More forecasters submit their forecasts to Bloomberg for nonfarm payrolls than for any other economic variable's release. It is also important to note that Bloomberg's methodology to rank professional forecasters is the same for all variables. Therefore, the results of this study could be applied for many other Bloomberg's rankings of economic forecasts.

Many professional forecasters (usually more than 60) submit their forecast, prior to nonfarm payrolls release announcement, to Bloomberg. Bloomberg published, for example, top-10 forecasters of nonfarm payrolls on October 08, 2010. (Note 2) According to the Bloomberg's report the following methodology has been employed to identify top-10 forecasters of nonfarm payrolls;

"To identify the top forecasters for this [nonfarm payrolls] index, we compiled estimates submitted to Bloomberg News over a two-year [September 2008-August 2010] period. We calculated the error for each forecast for by subtracting it from the actual figure. Then we totaled up the errors and divided it by the number of forecasts to drive each forecaster's average error. To qualify for the ranking, forecasters must have made at least 15 of the 24 forecasts. More than 60 forecasters were ranked."

Basically, Bloomberg calculated mean absolute error (MAE) and, as a result, a forecaster with the smallest MAE would be a winner (rank 1). The time period covered in the ranking was September 2008-August 2010. We reproduced the top-10 forecasters using Bloomberg methodology and covered the same time period, with results entered into Table 1B. The MAE of each of these top- 10 forecasters exactly matched with those of Bloomberg published ranks. In addition, we provide original forecasts along with actual release in the Table 1A. 
Table 1A. Original Real-Time Forecasts and Actual Release

\begin{tabular}{|c|c|c|c|c|c|c|c|c|c|c|c|}
\hline Date & $\begin{array}{c}\text { Credit } \\
\text { Agricole }\end{array}$ & $\begin{array}{l}\text { Morgan } \\
\text { Keegan }\end{array}$ & $\begin{array}{c}\text { Goldman } \\
\text { Sachs }\end{array}$ & $\begin{array}{l}\text { Wells } \\
\text { Fargo }\end{array}$ & $\begin{array}{c}\text { CIBC } \\
\text { World } \\
\text { Mkt }\end{array}$ & $\begin{array}{c}\text { MFC } \\
\text { Global }\end{array}$ & BBVA & $\begin{array}{c}\text { Action } \\
\text { Economics }\end{array}$ & $\begin{array}{c}\text { Deutsche } \\
\text { P AG }\end{array}$ & Natixis & $\begin{array}{l}\text { Actual } \\
\text { Release }\end{array}$ \\
\hline $8 / 31 / 2010$ & -106 & -106 & -125 & -107 & -120 & -50 & -90 & -90 & -90 & -80 & -54 \\
\hline $7 / 31 / 2010$ & -69 & -125 & -75 & -25 & -70 & -75 & -112 & -70 & -100 & -110 & -131 \\
\hline $6 / 30 / 2010$ & -200 & -178 & -100 & -130 & -140 & -115 & -60 & -160 & -50 & -150 & -125 \\
\hline $5 / 31 / 2010$ & 500 & 352 & 600 & 531 & 600 & 500 & 375 & 480 & 450 & 520 & 431 \\
\hline $4 / 30 / 2010$ & 200 & 189 & 175 & 200 & 200 & & 170 & 200 & 150 & 170 & 290 \\
\hline $3 / 31 / 2010$ & 180 & 184 & 200 & 177 & 175 & & 150 & 200 & 130 & 130 & 162 \\
\hline $2 / 28 / 2010$ & -100 & 5 & -100 & -29 & -25 & & -30 & -50 & 10 & 5 & -36 \\
\hline $1 / 31 / 2010$ & -20 & 5 & -25 & -68 & 0 & 25 & -10 & 0 & 10 & 15 & -20 \\
\hline $12 / 31 / 2009$ & & 21 & -25 & -24 & -25 & 15 & -20 & 0 & -30 & 20 & -85 \\
\hline $11 / 30 / 2009$ & -160 & -112 & -100 & -170 & -90 & -100 & -155 & -130 & -140 & -115 & -11 \\
\hline $10 / 31 / 2009$ & -175 & -163 & -200 & -208 & -200 & -160 & -185 & -150 & -180 & -180 & -190 \\
\hline $9 / 30 / 2009$ & -250 & -175 & -250 & -205 & -220 & -170 & -190 & -160 & -200 & -180 & -263 \\
\hline $8 / 31 / 2009$ & -230 & -224 & -250 & -306 & -275 & -250 & -205 & -200 & -220 & -175 & -216 \\
\hline $7 / 31 / 2009$ & -340 & -296 & -250 & -245 & -300 & -330 & -395 & -320 & -350 & -310 & -247 \\
\hline $6 / 30 / 2009$ & -440 & -378 & -425 & -370 & -375 & -400 & -385 & -340 & -390 & -300 & -467 \\
\hline $5 / 31 / 2009$ & & -482 & -475 & -540 & -520 & -530 & -530 & -500 & -540 & -515 & -345 \\
\hline $4 / 30 / 2009$ & -500 & -667 & -575 & -605 & -600 & & -632 & -600 & -620 & -550 & -539 \\
\hline $3 / 31 / 2009$ & -700 & -634 & -700 & -670 & -650 & & -658 & -640 & -650 & -660 & -663 \\
\hline $2 / 28 / 2009$ & -700 & -655 & -625 & -685 & -650 & -675 & -607 & -650 & -600 & -605 & -651 \\
\hline $1 / 31 / 2009$ & -475 & -586 & -475 & -575 & -550 & -550 & & -550 & -520 & -500 & -598 \\
\hline $12 / 31 / 2008$ & -600 & -578 & -550 & -550 & -500 & & & -480 & & -500 & -524 \\
\hline $11 / 30 / 2008$ & & & -400 & -450 & -350 & & & -350 & & -330 & -533 \\
\hline $10 / 31 / 2008$ & -250 & -183 & -300 & -283 & -200 & & & -220 & & -225 & -240 \\
\hline $9 / 30 / 2008$ & -80 & -113 & -150 & -150 & -120 & -120 & -90 & -100 & & -115 & -159 \\
\hline
\end{tabular}


Table 1B. The Forecasters' Ranking Based on the Bloomberg Methodology

\begin{tabular}{|c|c|c|c|c|c|c|c|c|c|c|}
\hline Date & $\begin{array}{c}\text { Credit } \\
\text { Agricole }\end{array}$ & $\begin{array}{l}\text { Morgan } \\
\text { Keegan }\end{array}$ & $\begin{array}{c}\text { Goldman } \\
\text { Sachs }\end{array}$ & $\begin{array}{l}\text { Wells } \\
\text { Fargo }\end{array}$ & $\begin{array}{c}\text { CIBC } \\
\text { World } \\
\text { Mkt } \\
\end{array}$ & $\begin{array}{c}\text { MFC } \\
\text { Global }\end{array}$ & BBVA & $\begin{array}{c}\text { Action } \\
\text { Economics }\end{array}$ & $\begin{array}{c}\text { Deutsche } \\
\text { P AG }\end{array}$ & Natixis \\
\hline $8 / 31 / 2010$ & 52 & 52 & 71 & 53 & 66 & 4 & 36 & 36 & 36 & 26 \\
\hline $7 / 31 / 2010$ & 62 & 6 & 56 & 106 & 61 & 56 & 19 & 61 & 31 & 21 \\
\hline $6 / 30 / 2010$ & 75 & 53 & 25 & 5 & 15 & 10 & 65 & 35 & 75 & 25 \\
\hline $5 / 31 / 2010$ & 69 & 79 & 169 & 100 & 169 & 69 & 56 & 49 & 19 & 89 \\
\hline $4 / 30 / 2010$ & 90 & 101 & 115 & 90 & 90 & & 120 & 90 & 140 & 120 \\
\hline $3 / 31 / 2010$ & 18 & 22 & 38 & 15 & 13 & & 12 & 38 & 32 & 32 \\
\hline $2 / 28 / 2010$ & 64 & 41 & 64 & 7 & 11 & & 6 & 14 & 46 & 41 \\
\hline $1 / 31 / 2010$ & 0 & 25 & 5 & 48 & 20 & 45 & 10 & 20 & 30 & 35 \\
\hline $12 / 31 / 2009$ & & 106 & 60 & 61 & 60 & 100 & 65 & 85 & 55 & 105 \\
\hline $11 / 30 / 2009$ & 149 & 101 & 89 & 159 & 79 & 89 & 144 & 119 & 129 & 104 \\
\hline $10 / 31 / 2009$ & 15 & 27 & 10 & 18 & 10 & 30 & 5 & 40 & 10 & 10 \\
\hline 9/30/2009 & 13 & 88 & 13 & 58 & 43 & 93 & 73 & 103 & 63 & 83 \\
\hline $8 / 31 / 2009$ & 14 & 8 & 34 & 90 & 59 & 34 & 11 & 16 & 4 & 41 \\
\hline $7 / 31 / 2009$ & 93 & 49 & 3 & 2 & 53 & 83 & 148 & 73 & 103 & 63 \\
\hline $6 / 30 / 2009$ & 27 & 89 & 42 & 97 & 92 & 67 & 82 & 127 & 77 & 167 \\
\hline $5 / 31 / 2009$ & & 137 & 130 & 195 & 175 & 185 & 185 & 155 & 195 & 170 \\
\hline 4/30/2009 & 39 & 128 & 36 & 66 & 61 & & 93 & 61 & 81 & 11 \\
\hline $3 / 31 / 2009$ & 37 & 29 & 37 & 7 & 13 & & 5 & 23 & 13 & 3 \\
\hline $2 / 28 / 2009$ & 49 & 4 & 26 & 34 & 1 & 24 & 44 & 1 & 51 & 46 \\
\hline $1 / 31 / 2009$ & 123 & 12 & 123 & 23 & 48 & 48 & & 48 & 78 & 98 \\
\hline $12 / 31 / 2008$ & 76 & 54 & 26 & 26 & 24 & & & 44 & & 24 \\
\hline $11 / 30 / 2008$ & & & 133 & 83 & 183 & & & 183 & & 203 \\
\hline $10 / 31 / 2008$ & 10 & 57 & 60 & 43 & 40 & & & 20 & & 15 \\
\hline 9/30/2008 & 79 & 46 & 9 & 9 & 39 & 39 & 69 & 59 & & 44 \\
\hline MAE & 54.9524 & 57.1304 & 57.2500 & 58.1250 & 59.3750 & 61.0000 & 62.4000 & 62.5000 & 63.4000 & 65.6667 \\
\hline Rank & 1 & 2 & 3 & 4 & 5 & 6 & 7 & 8 & 9 & 10 \\
\hline No of Forecasts & 21 & 23 & 24 & 24 & 24 & 16 & 20 & 24 & 20 & 24 \\
\hline
\end{tabular}

\subsection{Issues Related to the Current Bloomberg Methodology}

The current Bloomberg methodology is good if each of these 10 forecasters forecasted for all 24 months for nonfarm payrolls and then it could have been considered a balanced panel. Furthermore, the average error in a balanced panel would have based on 24 months for all forecasters and that would be a fair competition and hence, an accurate forecasters' ranking. In the present case, however, not all forecasters forecasted for 24 months. For instance, from Table 1B, Credit Agricole, which is the top forecaster according to Bloomberg, provided forecasts for 21 of the 24 months (3-months of missing forecasts) and MFC Global Investment (ranked $6^{\text {th }}$ by Bloomberg) only forecasted for 16 of the 24 months (8-months of forecasts were not submitted to Bloomberg). On the other hand, both Wells Fargo (ranked $4^{\text {th }}$ by Bloomberg) and Goldman Sachs (ranked $3^{\text {rd }}$ by Bloomberg) forecasted for all 24 months. Not all forecasters forecasted for all 24 months and hence it is an unbalanced panel. Furthermore, in an unbalanced panel, we should not use MAE (or root mean squared error (RMSE) or mean error (ME) as a forecast evaluation criterion. Since the numbers of forecasts are not equal for all forecasters in an unbalanced panel, it would not be fair for those who forecast more often than others due to the method used to treat forecast errors. In the case of the Bloomberg survey, 5 of the 10 forecasters did not forecast for all 24 months.

Missing forecasts for many months from several forecasters create two issues and these issues reduce the accuracy of the forecasters' ranking as well as the authenticity of the methodology currently employed by Bloomberg. The first issue related to Bloomberg's current methodology is that it, implicitly, considers a missing forecast (there is no submitted forecast) of a forecaster equal to a perfect forecast (forecast equals to actual release) of a forecaster for a given month. For instance, if a forecast equals the actual release then the forecast error (actual - forecast) will be zero for that month for a forecaster. On the other hand, if a forecaster does not submit a forecast to Bloomberg for a month then his/her forecast error for that month would be a missing value (in other words it would be a zero). As a result, if a forecaster makes a perfect forecast (which is extremely difficult (Note 3)) and that would equal a missing forecast (does not forecast, which is extremely easy) for a 
given month. Put simply, it is not equitable. This issue may discourage forecasting because some forecasters may skip a month or two, especially, during times of greater data volatility, because a forecaster may know in advance that a missing forecast would be treated, implicitly, as a perfect forecast. Therefore, there is an incentive not to forecast in volatile periods. As a result, this issue needs to addressed in a way such that no forecaster is getting rewarded being absent or penalized for submitting a forecast to Bloomberg.

The second issue related to the current Bloomberg methodology is that forecasters are competing against those forecasters whom do not submit forecasts to Bloomberg for a given month. Since, a missing forecast has a zero error, there is a disincentive to submitting a forecast to Bloomberg since there is a possible loss in competition against those who do not forecast that month (and equally if a forecaster makes a perfect forecast in a month, which is very rare). Therefore, we need a method that evaluates forecasts and yet limits the competition among those forecasters who actually forecasted for a given month.

In sum, the current Bloomberg ranking methodology has some serious issues and is unable to produce a fair and accurate forecasters' ranking in the case of an unbalanced panel.

\section{A New Approach to Rank Professional Forecasters in an Unbalanced Panel}

This study proposes a new approach which addresses the issues related to the Bloomberg methodology and provides a more rigorous, fairer and more accurate professional forecasters' ranking in the case of an unbalanced panel. This method can be used in any unbalanced panel and for any variable that is forecasted for any survey. Our methodology is based on ranks - where a lowest rank is associated with a smallest forecast error. For instance, a smallest absolute error would obtain rank 1 for a month and a smallest average rank of 24 months would be a winner ( $1^{\text {st }}$ position, most accurate forecaster).

Our methodology consists of three steps. In the first step, using the Bloomberg approach, the absolute error [Absolute (actual - forecast)] is calculated for each forecaster for all 24 months. For a comparison purpose, we use nonfarm payrolls forecast for the same time period (September 2008-August 2010) and for the top-10 forecasters which Bloomberg used in their ranking. (Note 4)

In the second step, we assign ranks to each forecast error for a month. The lowest rank is assigned to the smallest forecast error. For instance, the smallest forecast error would be assigned rank 1 and a largest forecast error would rank 10, assuming that all forecast errors are different from each other and all 10 forecasters make forecasts for that month. From Table 2A, for the 8/31/2010 period, MFC Global has the smallest forecast error and thereby is assigned rank 1. On the other hand, for the same month, Goldman Sachs has the largest forecast error and receives rank 7. (Note 5) Furthermore, if two or more forecasters tie for a rank (have same forecast error) then they will share the same rank. For example, from Table 2A, for the month of 8/31/2010, three professional forecasters (Action Economics, Deutsche Postbank and Natixis) have the same forecast error of 36K and it is the third smallest forecast error of that month. As a result, these three forecasters share the same rank of 3 for that month. In this step, we only rank those forecasters who submit their forecast to Bloomberg for a given month. That limits competition among those forecasters who forecasted for that month. Hence, this is a solution to the second problem related to the Bloomberg methodology. (Note 6)

We rank all 10 forecasters month-by-month for all 24 months and then we calculate an average rank for each of these 10 forecasters. This average rank is based on the number of forecasts a forecaster made in 24 months. We rank 10 forecasters based on this average rank and a forecaster with a lowest average rank would be the winner $\left(1^{\text {st }}\right.$ position or rank 1$)$ and a forecaster with a highest average rank would be a holder of last position $\left(10^{\text {th }}\right.$ position or rank 10). Moreover, we compared the ranking based on the new approach to those of the Bloomberg methodology. There are some significant changes of rankings for many forecasters, see Table $2 \mathrm{~A}$ for results. For instance, from Table 2A, Bloomberg declared Credit Agricole as number-1 forecasters (rank $1^{\text {st }}$ ) and our methodology assigned $8^{\text {th }}$ position (rank 8) to Credit Agricole. One major reason of these two different rankings of Credit Agricole from two different methodologies is that Credit Agricole did not forecast for all 24 months ( forecasted 21 of the 24 months) and Bloomberg ranking's approach rewarded Credit Agricole for being absent for three months. The new approach does not provide any incentives to not submit a forecast and thereby Credit Agricole's standing at $8^{\text {th }}$ position in the ranking is based on the new approach.

Another forecaster who experienced a significant change in his ranking based on these two approaches is CIBC World Markets (CIBC). The CIBC forecasted for all 24 months and Bloomberg assigned rank 5 for CIBC. On the other hand, our methodology declared CIBC as the winner (rank $\left.1^{\text {st }}\right)$. One major reason of this change in the ranking is that $\mathrm{CIBC}$ forecasted for all 24 months and competed against those forecasters who were absent in many months. This implies that CIBC was penalized by the Bloomberg methodology for forecasting all 24 months and our approach eliminates that penalty and provides a more accurate ranking. 
Overall, based on the new approach, 8 of the 10 forecasters experienced a change in their rankings and only Wells Fargo (rank 4 based on both ranking' approaches) and Deutsche Postbank (rank 9 in both cases) could manage to retain the same ranking in both methodologies, see Table $2 \mathrm{~A}$ for more detail.

Another interesting observation is that 5 of the 10 forecasters who forecasted for all 24 months, all 5 except Wells Fargo (which retains his ranking in both cases) positions improved based on the new approach compared to the Bloomberg methodology. For instance, CIBC move to $1^{\text {st }}$ position from $5^{\text {th }}$, Goldman Sachs to $2^{\text {nd }}$ from $3^{\text {rd }}$, Natixis to $6^{\text {th }}$ from $10^{\text {th }}$ and Action Economics to $7^{\text {th }}$ position from $8^{\text {th }}$. Three forecasters, who did not forecast for all 24 months forecasters lost their positions to a higher ranking (lesser accuracy) in our ranking compared to those of Bloomberg. The new positions are as Credit Agricole move to $8^{\text {th }}$ positions from $1^{\text {st }}$, Morgan Keegan to $5^{\text {th }}$ from $2^{\text {nd }}$ and MFC Global to $7^{\text {th }}$ from $6^{\text {th }}$. The other two forecasters, who did not forecast for all 24 months, are Deutsche Postbank (which maintains his rank 9 in both cases) and BBVA's rank improved to $3^{\text {rd }}$ from $7^{\text {th }}$.

Table 2A. The Forecasters' Ranking Based on the New Approach-Step 2

\begin{tabular}{|c|c|c|c|c|c|c|c|c|c|c|}
\hline Date & $\begin{array}{c}\text { Credit } \\
\text { Agricole }\end{array}$ & $\begin{array}{l}\text { Morgan } \\
\text { Keegan }\end{array}$ & $\begin{array}{c}\text { Goldman } \\
\text { Sachs }\end{array}$ & $\begin{array}{l}\text { Wells } \\
\text { Fargo }\end{array}$ & $\begin{array}{c}\text { CIBC } \\
\text { World } \\
\text { Mkt } \\
\end{array}$ & $\begin{array}{c}\text { MFC } \\
\text { Global }\end{array}$ & BBVA & $\begin{array}{c}\text { Action } \\
\text { Economics }\end{array}$ & $\begin{array}{c}\text { Deutsche } \\
\text { P AG }\end{array}$ & Natixis \\
\hline $8 / 31 / 2010$ & 4 & 4 & 7 & 5 & 6 & 1 & 3 & 3 & 3 & 2 \\
\hline $7 / 31 / 2010$ & 7 & 1 & 5 & 8 & 6 & 5 & 2 & 6 & 4 & 3 \\
\hline $6 / 30 / 2010$ & 8 & 6 & 4 & 1 & 3 & 2 & 7 & 5 & 8 & 4 \\
\hline $5 / 31 / 2010$ & 4 & 5 & 8 & 7 & 8 & 4 & 3 & 2 & 1 & 6 \\
\hline $4 / 30 / 2010$ & 1 & 2 & 3 & 1 & 1 & & 4 & 1 & 5 & 4 \\
\hline $3 / 31 / 2010$ & 4 & 5 & 7 & 3 & 2 & & 1 & 7 & 6 & 6 \\
\hline $2 / 28 / 2010$ & 7 & 5 & 7 & 2 & 3 & & 1 & 4 & 6 & 5 \\
\hline $1 / 31 / 2010$ & 1 & 5 & 2 & 9 & 4 & 8 & 3 & 4 & 6 & 7 \\
\hline $12 / 31 / 2009$ & & 8 & 2 & 3 & 2 & 6 & 4 & 5 & 1 & 7 \\
\hline $11 / 30 / 2009$ & 8 & 3 & 2 & 9 & 1 & 2 & 7 & 5 & 6 & 4 \\
\hline $10 / 31 / 2009$ & 3 & 5 & 2 & 4 & 2 & 6 & 1 & 7 & 2 & 2 \\
\hline 9/30/2009 & 1 & 7 & 1 & 3 & 2 & 8 & 5 & 9 & 4 & 6 \\
\hline $8 / 31 / 2009$ & 4 & 2 & 6 & 9 & 8 & 6 & 3 & 5 & 1 & 7 \\
\hline $7 / 31 / 2009$ & 8 & 3 & 2 & 1 & 4 & 7 & 10 & 6 & 9 & 5 \\
\hline $6 / 30 / 2009$ & 1 & 6 & 2 & 8 & 7 & 3 & 5 & 9 & 4 & 10 \\
\hline $5 / 31 / 2009$ & & 2 & 1 & 7 & 5 & 6 & 6 & 3 & 7 & 4 \\
\hline 4/30/2009 & 3 & 8 & 2 & 5 & 4 & & 7 & 4 & 6 & 1 \\
\hline $3 / 31 / 2009$ & 7 & 6 & 7 & 3 & 4 & & 2 & 5 & 4 & 1 \\
\hline 2/28/2009 & 8 & 2 & 4 & 5 & 1 & 3 & 6 & 1 & 9 & 7 \\
\hline $1 / 31 / 2009$ & 6 & 1 & 6 & 2 & 3 & 3 & & 3 & 4 & 5 \\
\hline $12 / 31 / 2008$ & 5 & 4 & 2 & 2 & 1 & & & 3 & & 1 \\
\hline $11 / 30 / 2008$ & & & 2 & 1 & 3 & & & 3 & & 4 \\
\hline $10 / 31 / 2008$ & 1 & 6 & 7 & 5 & 4 & & & 3 & & 2 \\
\hline $9 / 30 / 2008$ & 7 & 4 & 1 & 1 & 2 & 2 & 6 & 5 & & 3 \\
\hline Avg Rank & 4.66667 & 4.34783 & 3.83333 & 4.33333 & 3.58333 & 4.5 & 4.3 & 4.5 & 4.8 & 4.4166667 \\
\hline Rank & 8 & 5 & 2 & 4 & 1 & 7 & 3 & 7 & 9 & 6 \\
\hline Bloomberg & 1 & 2 & 3 & 4 & 5 & 6 & 7 & 8 & 9 & 10 \\
\hline Missing Forecast & 3 & 1 & 0 & 0 & 0 & 8 & 4 & 0 & 4 & 0 \\
\hline
\end{tabular}

\subsection{Step-3: A Penalty for a Missing Forecast}

Step 2 provided a solution to the second problem related to the Bloomberg methodology and limits the competition to those forecasters who forecasted in a given month. Step 3 provides a solution to the $1^{\text {st }}$ problem related to the current Bloomberg approach which is that a missing forecast equals to a perfect forecast - forecasters are getting rewarded being absent. Step 3 is an extension to the step 2 and in this step we calculate an average rank of a month and use that average rank for missing forecast for that month. For instance, for the month of 4/30/2010, 9 of the 10 forecasters, except MFC Global, forecasted for that month and the 
average rank of that month is 2.444 -based on 9 forecaster submissions. We use that average rank, which is 2.444, for the missing forecast, which is MFC Global, for that month. In other words, MFC Global's rank for the month of 4/30/2010 is 2.444, an average rank of that month, because MFC Global did not forecast that month. Therefore, we calculate an average rank of each of these 24 months and use an average rank of a month for those forecasters who were absent in that month. During 12 of the 24 months, one or more forecasters were absent and an average rank of a month were used for missing forecasts of that month, see Table $2 \mathrm{~B}$ for results. Maximum numbers of missing forecasts in a month are 5, only 5 forecasters forecasted for the month of 11/30/2008. The MFC Global has highest numbers of missing forecasts and it forecasted 16 of the 24 months (8 months of missing forecasts).

We calculate an average rank of a month based on available forecasts and use that rank for missing forecasts for that month. As a result, at the end, every forecaster has a rank for each of the 24 months. Furthermore, an average rank is calculated for all 10 forecasters and that average rank is based on 24 months. Therefore, no forecaster is getting rewarded for being absent or penalized for submitting forecast to Bloomberg for a given month. Hence, this offers one possible solution to the first problem related to the Bloomberg methodology.

Now the question arises; why use the average rank of a month for a missing forecast of that month? Is there any other solution? Another option/ penalty for a missing forecast for a month could have reversing the ranking. In other words, a highest possible rank (rank 10 in this case) is associated with a smallest possible forecast error and rank 1 (lowest possible rank) is assigned to a largest forecast error. Automatically, in this case, rank zero would be assigned to a missing forecast. Moreover, a forecaster with the largest average rank would be a winner in this case. The issues related to this approach are; (a) it is a harsh penalty and (b) penalty factor is constant for all months. This penalty factor is not perceived as fair because, first, the penalty factor is harsh because it treats a missing forecast equals to the worse forecast by assigning rank zero-exactly opposite to the Bloomberg approach. An indirect rank zero for a missing forecast of a month implies that an absent forecaster has a largest forecast error for that month. So it is perceived by the authors as too harsh and we need a middle way in the sense that a missing forecast should not be treated as a perfect forecast (like Bloomberg did) nor a worse forecast (like reverse ranking does). The second issue related to this penalty factor is that it is constant for all months. It is not fair because, in practice, sometimes a forecaster's forecast error may be smaller than others or vice versa and the average forecast error differs for different months. For example, May/June/September employment forecasts are typically the months associated with the largest forecast errors. 
Table 2B. The Forecasters' Ranking Based on the New Approach-Step 3

\begin{tabular}{|c|c|c|c|c|c|c|c|c|c|c|}
\hline Date & $\begin{array}{c}\text { Credit } \\
\text { Agricole }\end{array}$ & $\begin{array}{l}\text { Morgan } \\
\text { Keegan }\end{array}$ & $\begin{array}{c}\text { Goldman } \\
\text { Sachs }\end{array}$ & $\begin{array}{l}\text { Wells } \\
\text { Fargo }\end{array}$ & $\begin{array}{c}\text { CIBC } \\
\text { World } \\
\text { Mkt } \\
\end{array}$ & $\begin{array}{c}\text { MFC } \\
\text { Global }\end{array}$ & BBVA & $\begin{array}{c}\text { Action } \\
\text { Economics }\end{array}$ & $\begin{array}{c}\text { Deutsche P } \\
\text { AG }\end{array}$ & Natixis \\
\hline $8 / 31 / 2010$ & 4 & 4 & 7 & 5 & 6 & 1 & 3 & 3 & 3 & 2 \\
\hline $7 / 31 / 2010$ & 7 & 1 & 5 & 8 & 6 & 5 & 2 & 6 & 4 & 3 \\
\hline $6 / 30 / 2010$ & 8 & 6 & 4 & 1 & 3 & 2 & 7 & 5 & 8 & 4 \\
\hline $5 / 31 / 2010$ & 4 & 5 & 8 & 7 & 8 & 4 & 3 & 2 & 1 & 6 \\
\hline $4 / 30 / 2010$ & 1 & 2 & 3 & 1 & 1 & 2.444 & 4 & 1 & 5 & 4 \\
\hline $3 / 31 / 2010$ & 4 & 5 & 7 & 3 & 2 & 4.556 & 1 & 7 & 6 & 6 \\
\hline $2 / 28 / 2010$ & 7 & 5 & 7 & 2 & 3 & 4.444 & 1 & 4 & 6 & 5 \\
\hline $1 / 31 / 2010$ & 1 & 5 & 2 & 9 & 4 & 8 & 3 & 4 & 6 & 7 \\
\hline $12 / 31 / 2009$ & 4.222 & 8 & 2 & 3 & 2 & 6 & 4 & 5 & 1 & 7 \\
\hline $11 / 30 / 2009$ & 8 & 3 & 2 & 9 & 1 & 2 & 7 & 5 & 6 & 4 \\
\hline $10 / 31 / 2009$ & 3 & 5 & 2 & 4 & 2 & 6 & 1 & 7 & 2 & 2 \\
\hline 9/30/2009 & 1 & 7 & 1 & 3 & 2 & 8 & 5 & 9 & 4 & 6 \\
\hline $8 / 31 / 2009$ & 4 & 2 & 6 & 9 & 8 & 6 & 3 & 5 & 1 & 7 \\
\hline $7 / 31 / 2009$ & 8 & 3 & 2 & 1 & 4 & 7 & 10 & 6 & 9 & 5 \\
\hline $6 / 30 / 2009$ & 1 & 6 & 2 & 8 & 7 & 3 & 5 & 9 & 4 & 10 \\
\hline $5 / 31 / 2009$ & 4.556 & 2 & 1 & 7 & 5 & 6 & 6 & 3 & 7 & 4 \\
\hline $4 / 30 / 2009$ & 3 & 8 & 2 & 5 & 4 & 4.444 & 7 & 4 & 6 & 1 \\
\hline $3 / 31 / 2009$ & 7 & 6 & 7 & 3 & 4 & 4.333 & 2 & 5 & 4 & 1 \\
\hline $2 / 28 / 2009$ & 8 & 2 & 4 & 5 & 1 & 3 & 6 & 1 & 9 & 7 \\
\hline $1 / 31 / 2009$ & 6 & 1 & 6 & 2 & 3 & 3 & 3.667 & 3 & 4 & 5 \\
\hline $12 / 31 / 2008$ & 5 & 4 & 2 & 2 & 1 & 2.571 & 2.571 & 3 & 2.571 & 1 \\
\hline $11 / 30 / 2008$ & 2.6 & 2.6 & 2 & 1 & 3 & 2.6 & 2.6 & 3 & 2.6 & 4 \\
\hline $10 / 31 / 2008$ & 1 & 6 & 7 & 5 & 4 & 4 & 4 & 3 & 4 & 2 \\
\hline $9 / 30 / 2008$ & 7 & 4 & 1 & 1 & 2 & 2 & 6 & 5 & 3.444 & 3 \\
\hline Average & 4.5574 & 4.2750 & 3.8333 & 4.3333 & 3.5833 & 4.2247 & 4.1183 & 4.5000 & 4.5257 & 4.4167 \\
\hline Rank-2 & 10 & 5 & 2 & 6 & 1 & 4 & 3 & 8 & 9 & 7 \\
\hline Rank-1 & 8 & 5 & 2 & 4 & 1 & 7 & 3 & 7 & 9 & 6 \\
\hline Bloomberg & 1 & 2 & 3 & 4 & 5 & 6 & 7 & 8 & 9 & 10 \\
\hline
\end{tabular}

*Note: Average rank of a month is used for missing forecast in this analysis

On the other hand, an average rank of a month as a penalty factor for a missing forecast is a fair penalty factor because it is a flexible by month and not an extreme factor. As one would expect, an average monthly rank would be smaller for some months than others or vice versa. Such as, average month rank for 4/30/2010 period is 2.444 and it is a smallest one and a largest average monthly rank is 4.556 and it is for the months of 5/31/2009 and 3/31/2010. Therefore, an average monthly rank as a penalty factor for a missing forecast of a month is a fair and flexible approach. Moreover, it is not harsh — not treating missing forecast as a worse or perfect forecast.

The ranking based on the step 3 can be seen in Table $2 \mathrm{~B}$. The $1^{\text {st }}$ position is still occupied by the CIBC ( rank 1 and rank 5 based on the step 2 and Bloomberg, respectively) and the last position (rank 10) now goes to Credit Agricole, rank 8 and rank 1 based on step 2 and the Bloomberg methodology, respectively. Deutsche Postbank is the only forecaster who's ranking did not change in all three cases (rank 9 in Bloomberg, step 2 and step 3). The rest of the 9 forecasters did see a change in their ranking and some of these changes are significant. For instance, Credit Agricole rank 10 (based on step 3) vs. rank 1 (based on Bloomberg) and CIBC rank 1 (based on step 3) vs. rank 5 (based on Bloomberg), see Table 2B for more detail.

In sum, the current Bloomberg methodology is good for a balanced panel but not accurate for an unbalanced panel. In addition, traditional forecast evaluation criteria, such as, MAE, MSE or RMSE are good for a balanced panel but not fairly accurate for an unbalanced panel. Our approach provides a fair, rigorous and accurate forecasters ranking for any unbalanced panel. The ranking, based on the new approach, for many forecasters is significantly different than those of the Bloomberg's ranking. 


\section{The Concluding Remarks}

This paper proposes an attentive approach which provides a more rigorous and accurate professional forecasters' ranking in an unbalanced panel. Moreover, this study identifies some serious issues related to the current Bloomberg methodology. The top-10 forecasters of nonfarm payrolls are identified based on the new approach.

Our study sheds light on four important areas of professional forecasters' ranking. First, scheduled macroeconomic variables release announcements affect asset prices and volatility in financial markets and the impact is more significant when an actual release is different than market expectations and thereby the importance of an individual forecaster, who is better than consensus as well as other forecasters, is increased. In addition, a ranking from media services such as Bloomberg will be a strong evidence of forecasting accuracy for a professional forecaster. An accurate forecasters' ranking is also crucial for Bloomberg because accurate ranking would increase Bloomberg credibility as a source of market intelligence.

Second, our analysis discusses the current Bloomberg methodology. Third, issues related to the current Bloomberg methodology are discussed. The first issue related to the current Bloomberg methodology is that it considers, implicitly, a missing forecast equal to a perfect forecast for a given month. The second problem relates to the methodology is that for a given month a forecaster, who makes a forecast for that month, is competing against a forecaster who does not make a forecast for that month.

Finally, a new approach is proposed and the approach provides a more rigorous, fairer and more accurate forecasters' ranking in the case of an unbalanced panel. Our methodology is based on ranks-where a lowest rank is associated with a smallest forecast error for a given month. In the second step, for a given month, we rank only those forecasters who actually make a forecast for that month. That limits competition among those who forecasted and eliminates those who do not forecast for a given month. In the final step, we calculate the average rank for a month and use that average rank for those forecasters who do not submit their forecast to Bloomberg for that month. In that way no forecaster will get rewarded for being absent or penalized by submitting a forecast in times of greater data volatility. Hence it provides a solution to the first problem related to the current Bloomberg methodology.

We re-rank top-10 forecasters of nonfarm payrolls using the new approach. For many forecasters, the ranking based on our approach is significantly different than those of Bloomberg's ranking. For instance, Bloomberg declared Credit Agricole as a winner (rank 1) but the new approach assigned $10^{\text {th }}$ position (rank 10) to Credit Agricole. On the other hand, Bloomberg associated rank 5 to CIBC but the new approach declared CIBC as a winner (rank 1). One major reason of these two different rankings for a firm is that Credit Agricole does not forecast for all 24 months (forecasted for 21 months) and CIBC forecasted for all 24 months. Moreover, Credit Agricole may be getting rewarded in the Bloomberg methodology for being absent and CIBC penalized by submitting forecasts for all 24 months. On the other hand, our methodology does not give a reward for being absent nor penalize a forecaster for submitting a forecast and thereby provides a fairer, more rigorous and accurate ranking. Because a ranking should be based on forecast accuracy (on average smaller forecast error compared to others) and should not benefit absent forecasters or disadvantage those who make forecasts regularly.

In addition, traditional forecast evaluation criteria, such as, MAE, MSE or RMSE are good for a balanced panel but not accurate for an unbalanced panel. Our approach provides a more rigorous, fairer and more accurate forecasters' ranking in any unbalanced panel and for any economic variable.

\section{References}

Andersen, T., Tim Bollerslev, Francis Diebold, \& Clara Vega. (2007). Real-Time Price Discovery in Global Stock, Bond, and Foreign Exchange Markets. Journal of International Economics, 73(2), 251-77.

Bartolini, L., Linda Goldberg, \& Adam S. (2008). How Economic News Moves Markets. Current Issues in Economics and Finance, 14(6), Federal Reserve Bank of New York.

Rigobon, Roberto, \& Brian Sack. (2008). Noisy Macroeconomic Announcements, Monetary Policy, and Asset Prices. In John Campbell, ed., Asset Prices and Monetary Policy. NBER conference volume. Chicago: University of Chicago Press.

Schwert, G. W. (1981). The Adjustment of Stock Prices to Information About Inflation. Journal of Finance, 36, 15-29. 
Silvia, John, \& Iqbal, Azhar. (2010). Macroeconomic Forecasting, Consensus, and Individual Forecaster: A Real Time-Real World Approach. The 80th Annual Meetings of the Southern Economic Association, November 20-22, 2010, Atlanta, GA, USA.

\section{Notes}

Note 1. Rigobon and Sach (2008) and Bartolini at al. (2008) used Bloomberg consensus as a proxy for market expectations.

Note 2. The ranking was published in the "Bloomberg Brief Economics" see page 4 of the report. It is a Bloomberg publication. Bloomberg also published the methodology behind the ranking.

Note 3. A perfect forecast of nonfarm payrolls is extremely difficult in real-time. Only one forecaster only one-time could perfectly forecasted nonfarm payrolls in 24 months period and that was on $1 / 31 / 2010$. On the other hand, 5 forecasters have a total of 20 missing forecasts in 24 months period.

Note 4. We used the absolute error technique to calculate forecast errors because we followed Bloomberg (as they used this technique) and that also serves for comparison purposes. But our methodology can use any kind of technique to calculate forecast errors such as (actual - forecast) or (actual -forecast) ${ }^{2}$, etc. The final forecasters' ranking for a variable will be consistent for all these techniques.

Note 5 . The highest rank for this month $(8 / 31 / 2010)$ is 7 because a number of forecasters share the same forecast error therefore share the same rank.

Note 6. Note we do not impose a penalty for a missing forecast for a given month in this step. We will impose a penalty for a missing forecast in the next step, however. 